University of California, Hastings College of the Law UC Hastings Scholarship Repository

Faculty Scholarship

2008

\title{
Neuroimaging and Disorders of Consciousness: Envisioning an Ethical Research Agenda
}

Emily Murphy

University of California Hastings College of Law, murphyemily@uchastings.edu

Joseph J. Fins

Judy Iles

James L. Bernat

Joy Hirsch

See next page for additional authors

Follow this and additional works at: https://repository.uchastings.edu/faculty_scholarship

\section{Recommended Citation}

Emily Murphy, Joseph J. Fins, Judy Iles, James L. Bernat, Joy Hirsch, and Steven Laureys, Neuroimaging and Disorders of Consciousness: Envisioning an Ethical Research Agenda, 8 Amer. J. Bioethics 3 (2008).

Available at: https://repository.uchastings.edu/faculty_scholarship/1513

This Article is brought to you for free and open access by UC Hastings Scholarship Repository. It has been accepted for inclusion in Faculty Scholarship by an authorized administrator of UC Hastings Scholarship Repository. 
Authors

Emily Murphy, Joseph J. Fins, Judy Iles, James L. Bernat, Joy Hirsch, and Steven Laureys 


\title{
Neuroimaging and Disorders of Consciousness: Envisioning an Ethical Research Agenda
}

\author{
Joseph J. Fins, Weill Medical College of Cornell University* \\ Judy Illes, University of British Columbia* \\ James L. Bernat, Dartmouth Medical School** \\ Joy Hirsch, Columbia University** \\ Steven Laureys, University of Liege** \\ Emily Murphy, Stanford Law School**
}

The application of neuroimaging technology to the study of the injured brain has transformed how neuroscientists understand disorders of consciousness, such as the vegetative and minimally conscious states, and deepened our understanding of mechanisms of recovery. This scientific progress, and its potential clinical translation, provides an opportunity for ethical reflection. It was against this scientific backdrop that we convened a conference of leading investigators in neuroimaging, disorders of consciousness and neuroethics. Our goal was to develop an ethical frame to move these investigative techniques into mature clinical tools. This paper presents the recommendations and analysis of a Working Meeting on Ethics, Neuroimaging and Limited States of Consciousness held at Stanford University during June 2007. It represents an interdisciplinary approach to the challenges posed by the emerging use of neuroimaging technologies to describe and characterize disorders of consciousness.

Human consciousness encompasses subjectivity, sentience, self-awareness, and an ability to appreciate the relationship between the self and the environment. From a philosophical perspective, we appreciate the features of consciousness that enable the processing of information, access to information, content and phenomenal experience, qualia and awareness. From a cognitive neuroscience approach, we can determine different neural correlates relevant to these features of consciousness. Posner and colleagues (2006), for example, have attributed the mediation and orientation of attention (much like access) to a posterior attentional brain network and conscious awareness of attended objects to an anterior attentional network. Raichle (1998) attributes arousal consciousness to the ascending reticular formation and content consciousness to the engagement of cortical systems. Within these cortical networks, the fronto-parietal associative global workspace play a key role in the emergence of awareness (Laureys 2005).

Consciousness, however, is neither a momentary condition nor purely dispositional (Dennett 2001) but rather a phenomenon of variables that change over time. Consciousness is required for cognitive tasks involving working

${ }^{*}$ Co-lead authors.

**Equal authors in alphabetical order.

Acknowledgment: The authors acknowledge the support of the Greenwall Foundation for sponsorship of the conference on which this paper is based. Dr. Fins is a recipient of a Robert Wood Johnson Foundation Investigator Award in Health Policy Research and also gratefully acknowledges support from the Charles A. Dana and Buster Foundations. Dr. Illes acknowledges the additional support of NIH/NINDS RO1 NS\#045831. The meeting was hosted by the Stanford Center for Biomedical Ethics and Program in Neuroethics, Stanford University. Many thanks to Vivian Chin, Stanford University; Stephen Jones, Stanford University; Eugenie Marek, Stanford University; Navah Statman, National Alliance for Mental Illness, for attending; and Patricia Lau at the National Core for Neuroethics, University of British Columbia, for editorial assistance.

Cosigning Workshop Participants Martha J. Farah, University of Pennsylvania; Joseph T. Giacino, JFK Medical Center; Oleg Jardetsky, Stanford University; Albert R. Jonsen, California Pacific Medical Center; Maarten Lansberg, Stanford University; Sofia Lombera, Stanford University; David Magnus, Stanford University; Jennifer McCormick, Stanford University; Stephen J. Morse, University of Pennsylvania; Adrian M. Owen, Medical Research Council, UK; Eric Racine, Institut de Recherches Cliniques de Montréal, Montreal, Canada; Christine Wijman, Stanford University; Nicholas D. Schiff, Weill Cornell Medical College; William Winslade, University of Texas, Galveston. Address correspondence to Judy Illes, University of British Columbia, National Core for Neuroethics, 2211 Wesbrook Mall, Koerner, S124, Vancouver, BC V6T 2B5 Canada. E-mail: jilles@interchange.ubc.ca 
memory-the durable maintenance of information, novel combinations of operations, and intentional behavior. The interactions are dynamic and exist within a distributed neural network of circuits with unique capacities. Splitbrain studies suggest that the dominant (usually left) hemisphere may serve as the interpreter of the wide distribution of circuitry-associated events across the entire brain. Even when disconnected, this hemisphere seems to keep a running narrative of actions emotions, thoughts, and experiences (Gazzaniga 1998).

Much of our knowledge of the conscious brain is due to neuroimaging technologies. These include positron emission tomography (PET), which measures the brain's metabolic activity, oxygen extraction, or neurotransmitter activity; magnetoencephalography (MEG), which measures the magnetic fields generated by electrical activity within the brain; advanced magnetic resonance imaging (MRI) methods such as voxel-based volumetry or morphometry, which objectively quantify changes in brain structure; MR spectroscopy, which measures biomarker of neuronal integrity, cell membrane turnover, or energetic function; MR diffusion tensor imaging, which assesses the density, integrity, and directionality of white matter tracts (Laureys, Antoine et al. 2002); and functional MR imaging (fMRI), which quantifies blood-oxygenation-leveldependent (BOLD) changes.

Despite the availability of these many techniques and more than 30 years of work using one or more combinations of them to study the neural basis of consciousness, no single architecture has emerged as a unifying feature of conscious reflective performance in either healthy or states of disordered consciousness. Nevertheless, fMRI of the human injured brain has begun to transform how neuroscientists understand disorders of consciousness, such as the vegetative and minimally conscious states, and to deepen knowledge of mechanisms of recovery (Farah 2008; Laureys, Owen et al. 2004; Owen and Coleman 2008).

Over the past six years (2002-2007), studies of brain imaging and brain injury (Owen et al. 2006; Voss et al. 2006) have challenged assumptions about the immutability of severe injury (Fins, Schiff et al. 2007) as well as decades-old diagnostic categories (Jennett 2002; Multi-Society Task Force on PVS 1994). This scientific progress, and its potential clinical translation, presents an opportunity to better meet the needs of these historically marginalized patients (Fins 2003) and provide families with better diagnostic and prognostic information. It also presents an opportunity for ethical reflection about how best to responsibly translate these investigative methods into clinical practice. Although there are many issues that overlap with other marginalized populations, individuals with diminished levels of consciousness can be mistaken for the permanently unconscious. When this diagnostic and category error occurs, it is at the expense of neglected personhood, and thus obscures the values conflicts that should emerge when trying to define the choices about quality of life in states of diminished consciousness.
If we hope to address such values choices head on, we first need to articulate the ethical rationale for a sound diagnostic nosology and then describe how to achieve it using these new technological modalities in tandem with the clinical examination.

Drawing upon our work at a conference called "Ethics, Neuroimaging, and Limited States of Consciousness" at Stanford University during the summer of 2007, we provide here an ethical framework through which investigative neuroimaging techniques could mature into useful clinical tools for the diagnosis and treatment of those with disorders of consciousness. The framework has three elements: clinical translation, research challenges, and consent.

\section{ETHICS CHALLENGES IN CLINICAL TRANSLATION- THE UNCERTAIN SCOPE AND GOALS OF THE PROBLEM}

Although neuroimaging technology increasingly has been applied to the study of vegetative and minimally conscious patients, the scientific community still awaits precise figures on the epidemiology of these conditions. This data gap is reflective of one measure of the general neglect of this population (Fins 2003), though the scope of the problem is extensive. Estimates of the vegetative state in the United States range from 40 to 168 per million people (Beaumont and Kenealy 2005). A recent model of MCS prevalence in the United States was between 45,000 and 250,000 assuming a 10-year life expectancy (Fins, Master et al. 2007). These estimates may constitute a serious public health challenge, but it would be a mistake to see these conditions solely as a population-based concern. Disorders of consciousness inalterably affect individual families who grapple with care decisions, haunted by whether their loved ones are conscious and if they will recover understanding, speech, and a former self (Fins 2005, 2007b). Neuroimaging research on subjects with limited states of consciousness thus raises important clinical issues that we discuss next in the context of: (1) diagnosis and nosology, (2) prognosis and treatment effects, and (3) the pathophysiology of consciousness.

\section{Diagnosis and Nosology}

The current nosology of states of impaired consciousness is syndromic and results from findings on neurological examination. The diagnostic distinction between the unresponsiveness of patients in a vegetative state (VS) or a minimally conscious state (MCS) turns on the clinically observable evidence of the patient's conscious awareness. During a physical examination, clinicians assess patients' responsiveness to various stimuli and thereby reach conclusions of whether the patients' responses are simply "reflex" responses that do not require awareness or are "cognitive" or intentional responses that could be made only by an aware person (Bernat 2006). Examples of the former responses are "posturing" to noxious stimuli and a startle response such as eyeopening to a loud noise. Examples of the latter responses 
are sustained visual gaze, reaching for objects, gestured responses to questions, and appropriate emotional responses. Profoundly unresponsive patients showing only the former responses are diagnosed as VS, whereas those demonstrating some of the latter responses are diagnosed as MCS (Giacino et al. 2002).

Recent reports of functional neuroimaging studies in small numbers of subjects are beginning to change that distinction. A VS patient reported by Owen and colleagues (2006) and the VS patients reported by Di and colleagues (2007) likely were in MCS despite the absence of behavioral evidence of awareness on neurological examination. Thus, neuroimaging data may alter the criteria for diagnosis of VS and MCS and lead to a new nosology or, at least, a need to reach agreement on diagnostic criteria. This process includes defining how future neuroimaging results will complement the clinical assessment (Owen et al. 2007).

\section{Prognosis and Treatment Effects}

Prognosis in VS and MCS is similarly becoming informed by neuroimaging results (Bernat and Rottenberg 2007). Formerly, experiential studies established prognosis for recovery. For example, after studying published patient series and databases, the Multi-Society Task Force on PVS (1994) established probabilistic rules for predicting recovery of awareness in VS patients that depended on its duration and cause. The VS patient reported by Owen and colleagues (2006) and the two VS patients reported by Di and colleagues (2007) whose neuroimaging findings suggested that they were in MCS all showed clinical evidence of awareness several months later. An MR diffusion tensor imaging study by Voss and colleagues (2006) of a patient who spontaneously recovered conversational language 19 years following a traumatic brain injury (TBI) producing MCS convincingly demonstrated axonal sprouting in the posterior bihemispheric white matter. In this natural history example, the authors hypothesized that these changes help explain his unusual recovery. A patient reported by Schiff and colleagues (2007), who was in a stable MCS for six years following TBI, showed improved responsiveness and arousal following neuroimaging-guided deep brain stimulation of the thalamic intralaminar nuclei.

\section{Pathophysiology of Consciousness}

Our understanding of the anatomy and physiology of consciousness will be furthered by neuroimaging studies. We already know from single-patient studies that each braininjured patient has a unique pattern of brain injury. Patients who share a syndromic categorization (VS, MCS) may show a spectrum of functioning as a consequence of different areas and mechanisms of brain damage. Imaging studies can help elucidate these anatomic, physiologic, and functional differences to refine diagnostic frames relevant to predicting response to therapeutic interventions. These studies will improve the specificity of diagnostic categories and permit clinical neuroscientists and neurologists to individualize patient patterns of brain injury, amplifying what can productively be learned through a careful history and longitudinal neurological examinations. This translational effort linking bedside assessment to imaging will hopefully refine what are now crude clinical syndromes (Farah 2008).

Imaging techniques that might inform the human burden of disorders of consciousness warrant our collective attention. Whether they ever translate to the clinical mainstream from their use as an investigational tool remains an open question. In order to move in that direction, however, the clinical neuroscience community will have to reconcile new imaging findings against prevailing clinical paradigms about the minimally conscious and vegetative states.

\section{CHALLENGES IN BASIC NEUROIMAGING RESEARCH}

Despite hopes for the evolution of this technology and expectations fostered by media characterizations of imaging and consciousness in brain-injured patients (Racine et al. 2006; Singh et al. 2007), the translation of neuroimaging research to utility as a clinical tool is still in its infancy. The major challenges are patient selection, study design and standardization of the technology, including stimulus selection and experimental protocols. The current data pool derives from a small number of subjects and an equally limited number of investigative teams, which is reflective of the pervasive neglect of this population and the nihilistic assumption that all cases of severe brain injury will lead to fixed, inevitable, and catastrophic outcomes (Fins 2003). The underlying reason why the scope of this work has been limited largely to cross-collaborations between major teams in Cambridge, New York, and Liege is a matter for empirical analysis, is likely less a function of technological capability than intellectual interest and adequate resources to expand the scope of research.

\section{Patient Selection and Study Design}

The challenges for study design are significant. The hurdles in this kind of research reside with a nascent technology and a nosology of brain injury that remains descriptive. Unlike proper diagnostic categories that are specific, reproducible, and speak to scientific causality (Reiser 1997), imaging studies within single brain states can vary significantly depending upon the etiology of injury, anatomic locale, and time course (Fins 2007b; Laureys, Owen et al. 2004). Prematurely applying an emerging assessment tool to these clinical syndromic categories can potentially lead to diagnostic and prognostic confusion and category errors.

Appropriate study design is also dependent on the specific question asked. Conceptually linking the advancement of neuroimaging to the refinement of current descriptive categories is a key task. To make these categories more precise, specific imaging research findings need to be contextualized against established clinical diagnostic criteria - the best current benchmark for assessment (Giacino et al. 2002). Trials will need to be coupled with longitudinal protocols in which 
large patient numbers are available to characterize the evolution of brain states over time, and epidemiological studies to track changes in patient populations through the course of acute injury, rehabilitation, and chronic care (Fins 2005; Fins, Schiff et al. 2007).

Established criteria like the Multi-Society Task Force, coupled with longitudinal studies charting the natural history of recovery, can helpfully impose a Bayesian pretest probability upon imaging data and constrain diagnostic possibilities. For example, these constraints helped to place Owen and colleagues' (2006) neuroimaging findings of consciousness in a behaviorally vegetative TBI patient into an established clinical context. Using fMRI, these authors showed distributed network activations suggestive of consciousness. While the results at five months post-injury were provocative, they were diagnostically and prognostically plausible within time frames of recovery laid out by the Task Force and consistent with the patient's progression to MCS by behavioral criteria (Fins and Schiff, 2006). Systematic research into more precise, internationally coherent diagnostic categories will lead to the refinement of such criteria that are currently inconsistent (Giacino et al. 2002; Royal College of Physicians 2003) and to a better harmonization of inclusion and exclusion criteria for patient selection based on etiology and anatomy of injury, time after injury, and rehabilitative or therapeutic interventions.

\section{Standardization of Technology and Experimental Protocols and the Special Case of Pain Stimuli}

Standardization of the technical dimensions of neuroimaging is essential to achieve high-quality, comparable data sets. These dimensions are field strength, number of voxels (volumes), and regions of interest for mapping, statistical analysis, and a standardized and hierarchal repertoire of stimuli that follows on a continuum from simple to complex command following (Hirsch 2005). Variation in key parameters is shown in Table 1; determination of optimal parameters is an open challenge for the research community.

Choice of stimuli and experimental paradigms are also at the heart of the ethical challenges in basic neuroimaging research of patients in disordered states of consciousness. Studies using neutral stimuli such as listening to speech, imagining scenarios, or navigating through space may be relatively benign but are inherently difficult to reproduce reliably and interpret across research settings. Stimuli with positive valence are preferred to negative ones in studies of residual emotional processing, unless the use of emotionally painful stimuli are the object of the study or if they show proven benefit in terms of robustness of the obtained neural response.

As challenging as executing these studies may be, those of physical pain in disorders of consciousness are a special case as comatose, vegetative, and minimally conscious patients, by definition, are unable to communicate their possible suffering (Laureys and Boly 2007). Unlike any other group, the potential disconnect between lived cognitive experience and an ability to communicate what one feels and perceives makes the study of pain in diminished states of consciousness especially important. The prospect remains that patients may perceive and experience pain in MCS that their bodies cannot express through usual channels of communication. Only the astute clinical observer would note the distress of a dilated pupil or other physiologic signs of sympathetic discharge such as an increased heart rate. These signs can be subtle and multifactorial. For example, an elevated heart rate could be due to a fever, low blood volume, or pain and the differential is often hard to accurately discern. The use of neuroimaging technologies and the identification of pain networks could become an important adjuvant to the assessment of pain in this population cut off from an ability to communicate. This discordance between what the patient or subject might experience and what he might be able to express makes the study of pain of compelling ethical import in this population. These issues merit special discussion because of the potential burdens experienced by these patients and the deontological fiduciary obligations imposed on clinicians to identify and respond to patient distress.

The goal of pain research is to acquire new knowledge on the mechanisms, pathogenesis, diagnosis, and treatment of pain, which may translate to direct clinical benefit. At present, however, there is no evidence-based knowledge for guiding decisions regarding the management of pain in patients in disordered states of consciousness (Schnakers and Zasler 2007). Two functional neuroimaging studies specifically explored brain processing linked to pain in the vegetative state. Results were contradictory. Laureys, Faymonville and colleagues (2002) compared cerebral activation to highintensity electrical stimulation of the median nerve at the wrist in 15 vegetative patients with 15 healthy volunteers. Results showed preserved and robust activation of subcortical (brainstem and thalamus) and cortical (limited to the primary somatosensory areas) areas in each and every patient. However, the residual cortical activation was like an island, disconnected from the rest of the "pain matrix" —including the anterior cingulate cortex, considered critical in the affective and cognitive processing of pain (Vogt 2005) — and the higher order cortical network considered necessary for conscious processing (Laureys 2005). Kassubek and colleagues (2003) used a similar methodology in seven vegetative patients and confirmed activation in primary somatosensory cortex but also-and surprisingly-in secondary somatosensory, insular, and anterior cingulate cortices.

Noxious stimuli must adhere to the published standards of the International Association for the Study of Pain (IASP) Ethical Guidelines for Pain Research in Humans (Charlton 1995). The minimal intensity of noxious stimulus necessary to achieve the goals of the study should be established, with patient comfort fundamentally a central priority. Notwithstanding ethical considerations, such basic research has been faced with paradoxical restrictions. In some research settings, noxious stimuli cannot be applied to patients unable 
Table 1. Representative Neuroimaging Studies of Patients in Disordered States of Consciousness

\begin{tabular}{|c|c|c|c|c|c|c|}
\hline $\begin{array}{l}\text { Author, } \\
\text { year }\end{array}$ & Modality & $\begin{array}{c}\text { Field } \\
\text { strength }\end{array}$ & Stimuli & $\begin{array}{l}\text { Number of } \\
\text { subjects }\end{array}$ & $\begin{array}{l}\text { Reported } \\
\text { diagnosis }\end{array}$ & Controls \\
\hline Schnakers et al. 2008 & PET & - & Amantadine trial & $1 \mathrm{MCS}$ & & 64 \\
\hline Ammermann et al. 2007 & MRI & $1.5 \mathrm{~T}$ & Resting & $\begin{array}{l}12 \text { (3 VS, } 7 \\
\text { PVS, } 2 \text { MCS) }\end{array}$ & VS and MCS & \\
\hline Coleman et al. 2007 & fMRI & $3.0 \mathrm{~T}$ & $\begin{array}{l}\text { Two speech conditions } \\
\text { (high-ambiguity } \\
\text { sentences, } \\
\text { low-ambiguity } \\
\text { sentences) and } \\
\text { unintelligible noise } \\
\text { condition }\end{array}$ & $\begin{array}{l}14 \text { (7 VS, } 5 \\
\text { MCS, } 2 \\
\text { severely } \\
\text { disabled, } \\
\text { emerged from } \\
\text { MCS) }\end{array}$ & $\begin{array}{l}\text { VS, MCS, and } \\
\text { severely } \\
\text { disabled }\end{array}$ & \\
\hline Di et al. 2007 & fMRI & 1.5 & Auditory (own name) & $\begin{array}{l}7 \mathrm{VS} \text { and } 4 \\
\text { MCS }\end{array}$ & & None \\
\hline Hildebrandt et al. 2007 & $\begin{array}{l}\text { SPECT, VEP, } \\
\text { ERP }\end{array}$ & $\mathrm{N} / \mathrm{A}$ & Visual stimulation & $\begin{array}{l}21 \text { (13 in VS, } 8 \\
\text { recovered) }\end{array}$ & $\begin{array}{l}\text { VS and } \\
\text { recovered } \\
\text { from VS }\end{array}$ & \\
\hline Wu et al. 2007 & fMRI & - & $\begin{array}{l}\text { Visual stimulation } \\
\text { (Article in Chinese) }\end{array}$ & 9 & MCS & 10 \\
\hline Owen et al. 2006 & fMRI & $3 \mathrm{~T}$ & $\begin{array}{l}\text { Instructed to imagine } \\
\text { playing tennis and } \\
\text { moving around her } \\
\text { home }\end{array}$ & 1 & VS & 34 \\
\hline Staffen et al. 2006 & fMRI & $1.5 \mathrm{~T}$ & $\begin{array}{l}\text { Own name stimuli, } \\
\text { other name stimuli, } \\
\text { silent null events }\end{array}$ & 1 & VS & 3 \\
\hline Voss et al. 2006 & $\begin{array}{l}\text { DTI-MRI, } \\
\text { PET-CT }\end{array}$ & $3.0 \mathrm{~T}$ & None & 2 & MCS & 20 \\
\hline Juengling et al. 2005 & $\begin{array}{l}\text { MRI, } \\
\text { FDG-PET }\end{array}$ & $1.5 \mathrm{~T}$ & Resting & 5 & VS & \\
\hline Schiff et al. 2005 & fMRI & $1.5 \mathrm{~T}$ & $\begin{array}{l}\text { Light touch of both } \\
\text { hands, auditory stimuli } \\
\text { with narrative read by } \\
\text { family members and } \\
\text { then backwards (no } \\
\text { language-related } \\
\text { content) }\end{array}$ & 2 & MCS & 7 \\
\hline Bekinschtein et al. 2004 & fMRI & $1.5 \mathrm{~T}$ & Words vs. silence & 1 & MCS & \\
\hline Boly et al. 2004 & PET & - & Auditory (noise) & $\begin{array}{l}15 \mathrm{VS} \text { and } 5 \\
\text { MCS }\end{array}$ & & 15 \\
\hline $\begin{array}{l}\text { Laureys, Perrin et al. } \\
2004\end{array}$ & PET & - & $\begin{array}{l}\text { Auditory: } \\
\text { noise/cries/own name }\end{array}$ & $1 \mathrm{MCS}$ & & None \\
\hline Kassubek et al. 2003 & PET, MRI & $1.5 \mathrm{~T}$ & $\begin{array}{l}\text { Painful stimuli } \\
\text { (electrical) }\end{array}$ & 7 & VS & \\
\hline Schiff et al. 2002 & $\begin{array}{l}\text { FDG-PET, } \\
\text { MRI, MEG }\end{array}$ & - & $\begin{array}{l}\text { Bilateral auditory, } \\
\text { unilateral } \\
\text { somatosensory (tactile } \\
\text { stimulation) }\end{array}$ & 5 & VS & $\begin{array}{l}\text { Yes } \\
\text { (unspecified } \\
\text { number) }\end{array}$ \\
\hline $\begin{array}{l}\text { Laureys, Faymonville } \\
\text { et al. } 2002\end{array}$ & PET and MRI & $1.5 \mathrm{~T}$ & $\begin{array}{l}\text { Noxious somatosensory } \\
\text { stimuli }\end{array}$ & $\begin{array}{l}15 \\
\text { (Nonsedated) }\end{array}$ & VS & 15 \\
\hline Schiff et al. 1999 & $\begin{array}{l}\text { PET, MRI, } \\
\text { and MEG }\end{array}$ & $1.5 \mathrm{~T}$ & $\begin{array}{l}\text { Resting, auditory, single } \\
\text { somatosensory stimuli } \\
\text { applied to the left index } \\
\text { finger }\end{array}$ & 1 & VS & \\
\hline
\end{tabular}


to give written informed consent. In clinical practice, however, the exploration of behavioral responses to nociceptive stimuli (e.g., applying pressure to the fingernail bed with a pencil, applying pressure to the supraorbital ridge or jaw angle, pinching the trapezium, or rubbing the sternum) is a procedure that is routinely used to diagnostically evaluate the level consciousness in these patients. Reactivity to pain, for example, is part of widely used "consciousness scales" such as the Glasgow Coma Scale (Teasdale and Jennett 1974) and Coma Recovery Scale-Revised (Giacino et al. 2004).

Pain research in patients with disordered consciousness may offer the prospect of clinical benefit via improved pain management. Considering the current lack of scientific evidence, some investigators (Panksepp et al. 2007; Schnakers and Zasler 2007) propose pain treatment in all vegetative and minimally conscious patients, but this view is not shared by clinical guidelines (Multi-Society Task Force on PVS 1994). Pain control using analgesic ladders (World Health Organization 1990), a presumptively reasonable approach, is at present not incorporated in symptomatic, palliative, or end-of-life care of these patients; e.g., Terry Schiavo died without administration of strong opiates. Systematic use of opioid analgesics in these patients might lead to undesired sedation and subsequent underestimation of the level of consciousness. On the contrary, some patients might experience hyperalgesia, requiring more aggressive analgesic therapy, and some patients might fail to show signs of consciousness and be misdiagnosed because the presence of severe pain might further decrease their already impaired cognitive functioning (Laureys et al., unpublished observations). Neuropalliative vigilance is especially critical as patients progress from one brain state to the next and develop more robust means to process noxious threats from the environment (Fins 2005).

The research challenges in neuroimaging of disordered consciousness are substantial but not insurmountable. Nosological and technological inconsistencies can be reconciled through researcher and institutional collaboration. The ethical challenges to conducting research in patients whose inability to participate in or withdraw from research through traditional voluntary, behavioral means are inherent both to their protection and their inclusion, as discussed next.

\section{INFORMED CONSENT AND JUSTICE IN RESEARCH}

Engaging in a research enterprise that is focused on individuals in varying states of consciousness will pose ethical challenges most notably because of the decisional incapacity of the subjects. The nefarious legacy of research ethics abuses of those who have been unable to defend their interests because of the dual vulnerabilities of incompetence and institutionalization provides historical caution (Jonsen 1998). We reaffirm in the strongest terms the import of human subjects protections for this population, while affirming the right of access to study participation, even when there is not the prospect of direct medical benefit (Miller and Fins 1999).
Although informed consent has been viewed as a remedy to this legacy of abuse (Miller and Fins 1999), consent remains unavailable in this population because of decisional incapacity. However, the inability to provide consent should not be viewed as a categorical prohibition against research participation. It is ethically legitimate to study this population, as long as procedural safeguards are in place for appropriate surrogate authorization (Fins 2000; 2007a; Miller and Fins 2005). For research that carries more than minimal risk but does not have the prospect of direct medical benefit, the use of a consensus model of consent requiring the agreement of four parties is one approach to achieve this goal: the subject's legally authorized representative, the subject's physician, the clinical investigator, and a lay subject advocate (Fins and Miller 2000).

Enfranchising the decisionally incapacitated into the research enterprise is consistent with the ethical principles governing the National Commission for the Protection of Human Subjects of Biomedical and Behavioral Research's landmark 1978 Belmont Report. Belmont sought to ensure the just distribution of research ethics risks across all populations and to safeguard the vulnerable among us. Modernday regard for distributive justice urges the inclusion of marginalized communities and fair access to biomedical research for those with neuropsychiatric disorders (Michels 1999; National Bioethics Advisory Commission 1998).

The inclusion of such subjects into the research enterprise is also consistent with the growing appreciation that subjects who are minimally conscious may in fact demonstrate through their behaviors only minimal evidence of their cognitive processes. The ethical challenge for investigators is to study this population to learn more about their cognitive capabilities and to include these subjects, as they are able, in the consent or assent process, recognizing that subjects may reveal a greater capability to engage with the investigative team. Exemplifying this possibility is the patient in the Owen and colleagues (2006) study who was vegetative by clinical exam but at minimum consciousness on functional imaging.

Paradoxically, then, though understandably, those with disorders of consciousness often have been protected from the research enterprise by regulatory exclusion, which inverts the justice ethos of Belmont. To counter the displacement of ethical reasoning by ill-fitting regulatory oversight (de Melo-Martin et al. 2007), we maintain the need for inclusion of decisionally incapacitated subjects in research as long as it is ethically proportionate and attentive to foreseeable risks and benefits. This determination hinges on the accurate assessment of risk; notably, that most neuroimaging studies pose little more than a minor increment over minimal risk, which is a useful category in the federal regulations governing research with children (Code of Federal Regulations 45CFR46 1991). With this degree of risk, it would be ethically proportionate to perform studies, without the prospect of direct medical benefit to an individual subject, if knowledge gained would advance the understanding of disorders of consciousness and provide indirect benefits to surrogates about the condition of their loved ones. Due attention should 
also be paid to recoveries that might reconstitute decisionmaking capacity and the ability to provide meaningful consent or even a less robust assent (Fins et al. 2006).

We caution against suggesting therapeutic intent when there is none and thus fostering a therapeutic misconception (Appelbaum et al. 2004). Actively disabusing surrogates of such misconceptions is an even stronger goal. We urge collaboration between investigators and ethicists that promotes frank discussion of the challenges posed by research in subjects with decisional incapacity. While it is ethically inappropriate to exploit a vulnerable population that is unable to provide informed consent, consent may not be unobtainable in subjects whose disorder of consciousness merits empirical investigation.

\section{CONCLUSIONS: CHOICES, TRANSPARENCY, AND COLLABORATION}

With the many remaining uncertainties that relate to basic science studies, clinical goals, and consent, transparency and close collaboration with patient families about the ethical challenges posed by this research are necessary to identify values choices that are obscured through errors of diagnostic omission. When properly diagnosed, questions will arise about quality of life in these states of diminished consciousness, how long one should wait for recovery, and what constitutes meaningful recovery. Although some would prefer that these questions remain unasked, we believe that it is a question of intellectual commitment to present families with the full scope of available information in order to maintain their trust and acknowledge their ethical standing as decision-makers for those who are unable to make choices for themselves.

Families who care for patients with severe brain injury carry a heavy burden of medical decision-making (Levine 1999). They are entitled to support and the exchange of information that is both scientifically informed and compassionately communicated. To address these challenges within the framework we have provided here, and achieve the goal of maximizing the potential of imaging research of altered states of consciousness, we conclude with the following recommendations:

- An interdisciplinary panel of experts is needed to define clear milestones for moving the technology forward along the research-to-translation trajectory in its application to limited states of consciousness. This panel should consist of investigators actively advancing functional neuroimaging for VS and MCS, other scientists and physicians, and stakeholders from the public. Progress reviews are needed on a regular basis and on as-needed basis if and when groundbreaking findings are discovered. This body should also act as a clearinghouse of information to ensure accuracy of press coverage as needed.

- In response to the remaining possibility that patients with disorders of consciousness might fail to receive accurate longitudinal diagnoses and the relative absence of reproducible predictors of recovery, we call upon the World
Health Organization to articulate standards of care for this population. We further call upon the medical publishing community, represented by the Vancouver Group and its successors (International Committee of Medical Journal Editors 2007), to articulate international standards for publications related to patient selection, acquisition protocols, and stimuli.

- Specialized education and information tools that mitigate therapeutic illusions, extravagance, futility, neglect, and even nihilism are needed for physicians and families (Illes et al. 2008).

- Guidance for resource allocation should be sought through forums open for public engagement and scrutiny.

- Cost-benefit analysis studies should be undertaken to determine ongoing costs of care for patients in MCS and how novel neuroimaging technologies influence these factors across different health care systems. In the United States, such studies could be underwritten, for example, by the Agency for Health Care Research and Quality (AHRQ) of the National Institutes of Health and in Canada by the Institute for Health Services and Policy Research (IHSPR) of the Canadian Institutes for Health Research.

- Consideration should be given to the downstream legal ramifications of emerging neurotechnologies, including the eventual need to incorporate the evolution of these technologies in advance care planning utilizing durable powers of attorney for healthcare and living wills.

The humanistic dimensions of the interactions between scientists, physicians, and families cannot be overstated. Emerging knowledge about brain states will heighten expectations for some families and bring tremendous disappointment to others. Investigators and clinicians need to be aware of the power of their words, impressions, and their interlocutors' tolerance for ambiguity. Findings should be shared with caution and humility, in order to foster trust and reciprocity (Illes and Chin 2007). Conversations should always stress the limitations of the data and their current inability to give voice to the patient's inner life (Fins and Schiff 2006; Naccache 2006). Although we sympathize with the desire of families to know, the clinical investigator's task is to avoid speculation. Our collective task is to transform the speculative into new knowledge about disorders of consciousness and then determine how to communicate responsibility with both scientific and lay audiences. This charge should also be part of the research agenda.

How should we handle the inherent uncertainty as this technology evolves? We must appreciate that consciousness as a unitary construct is unreachable and rather pursue a neurobiology of individual cognitive phenomena that together create human consciousness: sensory and information experience, processing, intention, motivation, response, compensatory and reflective use of feedback.

\section{REFERENCES}

Ammermann, H., J. Kassubek, M. Lotze, E. Gut, M. Kaps, J. Schmidt, F. A. Rodden, and W. Grodd. 2007. MRI brain lesion patterns in 
patients in anoxia-induced vegetative state. Journal of the Neurological Sciences 260(1-2): 65-70.

Appelbaum, P. S., Lidz, C. W. and Grisso T. 2004. Therapeutic misconception in clinical research: Frequency and risk factors. IRB 26(2): $1-8$.

Beaumont, J. G., and Kenealy, P. M. 2005. Incidence and prevalence of the vegetative and minimally conscious states. Neuropsychological Rehabilitation 15(3-4): 184-189.

Bekinschtein, T., Leiguarda, R., Armony, J., Owen, A., Carpintiero S., Niklison J., Olmos L., Sigman L., and Manes F. 2004. Emotion processing in the minimally conscious state. Journal of Neurology, Neurosurgery, and Psychiatry 75(5): 788.

Bernat, J. L. 2006. Chronic disorders of consciousness. Lancet 9517: 1181-1192.

Bernat, J. L., and Rottenberg, D. A. 2007. Conscious awareness in PVS and MCS: The borderlands of neurology. Neurology 68(12): 885886.

Boly, M., Faymonville, M. E., Peigneux, P., Lambermont, B., Damas, P., Del Fiore, G., Degueldre, C., Franck, G., Luxen, A., Lamy, M., Moonen, G., Maquet, P., and Laureys, S. 2004. Auditory processing in severely brain injured patients: Differences between the minimally conscious state and the persistent vegetative state. Archives of Neurology 6(2): 233-238.

Charlton, E. 1995. Ethical guidelines for pain research in humans. Committee on Ethical Issues of the International Association for the Study of Pain. Pain 63(3): 277-278.

Code of Federal Regulations 45CFR46. Subpart D. 1991. Additional DHHS protections for children involved as subjects in research. Washington, DC: U.S. Department of Health and Human Services.

Coleman, M. R., Rodd, J. M., Davis, M. H., Johnsrude, I. S., Menon, D. K., Pickard, J. D., and Owen, A. M. 2007. Do vegetative patients retain aspects of language comprehension? Evidence from fMRI. Brain 130(Pt 10): 2494-2507.

de Melo-Martin, I., Palmer, L. I., and Fins, J. J. 2007. Viewpoint: Developing a research ethics consultation service to foster responsive and responsible clinical research. Academic Medicine: Journal of the Association of American Medical Colleges 82(9): 900-904.

Dennett, D. 2001. Are we explaining consciousness yet? Cognition 79(1-2): 221-237.

Di, H. B., Yu, S. M., Weng, X. Z., Laureys, S., Yu, D., Li, J. Q., Qin, P. M., Zhu, Y. H., Zhang, S. Z., and Chen, Y. Z. 2007. Cerebral response to patient's own name in the vegetative and minimally conscious states. Neurology 68: 895-899.

Farah, M. J. 2008. Neuroethics and the problem of other minds: Implications of neuroscience for the moral status of brain-damaged patients and nonhuman animals Neuroethics 1(1): 9-18.

Fins, J. J. 2000. A proposed ethical framework for international cognitive neuroscience: A consideration of deep brain stimulation in impaired consciousness. Neurological Research 22: 273-278.

Fins, J. J. 2003. Constructing an ethical stereotaxy for severe brain injury: Balancing risks, benefits and access. Nature Reviews Neuroscience 4(4): 323-327.
Fins, J. J. 2005. Clinical pragmatism and the care of brain damaged patients: Toward a palliative neuroethics for disorders of consciousness. Progress in Brain Research 150: 565-582.

Fins, J. J. 2007a. Testimony before the House Committee on Veterans' Affairs on Traumatic Brain Injury. Washington, DC.

Fins, J. J. 2007b. A review of: Woodruff, L. \& Woodruff, B. In an instant: A family's journey of love and healing (Random House, New York, 2007). Journal of the American Medical Association 297: 26422643.

Fins, J. J., Giacino, J., Rezai, A., and Schiff, N. 2006. Ethical insights from a neuromodulation clinical trial to restore function in the minimally conscious state (MCS). Abstract 182.3/LL35. Atlanta, GA: Society for Neuroscience.

Fins, J. J., Master, M. G., Gerber, L. M., and Giacino, J. T. 2007. The minimally conscious state: A diagnosis in search of an epidemiology. Archives of Neurology 64(10): 1400-1405.

Fins, J. J., and Miller, F. G. 2000. Enrolling decisionally incapacitated subjects in neuropsychiatric research. CNS Spectrums 5(10): 32-40.

Fins, J. J., and Schiff, N. D. 2006. Shades of gray: New insights into the vegetative state. The Hastings Center Report 36(6): 8.

Fins, J. J., Schiff, N. D., and Foley, K. M. 2007. Late recovery from the minimally conscious state: Ethical and policy implications. Neurology 68(4): 304-307.

Gazzaniga, M. S. 1998. Brain and conscious experience. Advances in Neurology 77: 181-192.

Giacino, J. T., Ashwal S., Childs N., Cranford R., Jennett B., Katz D. I., Kelly J. P., Rosenberg J. H., Whyte J., Zafonte R. D., and Zasler N. D. 2002. The minimally conscious state: definition and diagnostic criteria. Neurology 58(3): 349-353.

Giacino, J. T., Kalmar., and Whyte, J. 2004. The JFK Coma Recovery Scale-Revised: Measurement characteristics and diagnostic utility. Archives of Physical Medicine and Rehabilitation 85(12): 20202029.

Hildebrandt, H., Happe, S., Deutschmann, A., Basar-Eroglu, C., Eling, P., and Brunhober, J. 2007. Brain perfusion and VEP reactivity in occipital and parietal areas are associated to recovery from hypoxic vegetative state. Journal of the Neurological Sciences 260(1-2): 150-158.

Hirsch, J. 2005. Raising consciousness. The Journal of Clinical Investigation. 115(5): 1102.

Illes, J., and Chin, V. N. 2007. Trust and reciprocity: Foundational principles for human subjects imaging research. The Canadian Journal of Neurological Sciences 34(1): 3-4.

Illes, J., Lau, P. W., and Giacino, J. T. 2008. Ethics in the revolution of neuroimaging and disorders of consciousness. Nature Clinical Practice Neurology. In press.

International Committee of Medical Journal Editors. 2007. Uniform requirements for manuscripts submitted to biomedical journals: Writing and editing for biomedical publication. Available at: http:/ /www.icmje.org (accessed May 8, 2008).

Jennett, B. 2002. The vegetative state. New York, NY: Cambridge University Press. 
Jonsen, A. R. 1998. The birth of bioethics. New York, NY: Oxford University Press.

Juengling, F. D., Kassubek, J., Huppertz, H. J., Krause, T., and Els, T. 2005. Separating functional and structural damage in persistent vegetative state using combined voxel-based analysis of 3-D MRI and FDG-PET. Journal of the Neurological Sciences 228(2): 179-184.

Kassubek, J., Juengling, F. D., Els, T., Spreer, J., Herpers, M., Krause, T., Moser, E., and Lucking, C. H. 2003. Activation of a residual cortical network during painful stimulation in long-term postanoxic vegetative state: A 15O-H2O PET study. Journal of the Neurological Sciences 212(1-2): 85-91.

Laureys, S. 2005. The neural correlate of (un)awareness: Lessons from the vegetative state. Trends in Cognitive Sciences 9(12): 556559.

Laureys, S., Antoine, S., Boly, M., Elincx, S., Faymonville, M. E., Berre, J., Sadzot, B., Ferring, M., De Tiege, X.,van Bogaert, P., Hansen, I., Damas, P., Mavroudakis, N., Lambermont, B., Del Fiore, G., Aerts, J., Degueldre, C., Phillips, C., Franck, G., Vincent, J. L., Lamy, M., Luxen, A., Moonen, G., Goldman, S., and Maquet, P. 2002. Brain function in the vegetative state. Acta Neurologica Belgica 102(4): 177185.

Laureys, S., and Boly M. 2007. What is it like to be vegetative or minimally conscious? Current Opinion in Neurology 20(6): 609-613.

Laureys, S., Faymonville, M. E., Peigneux, P., Damas, P., Lambermont, B., Del Fiore, G., Degueldre, C., Aerts, J.,Luxen, A., Franck, G., Lamy, M., Moonen, G., and Maquet, P. 2002. Cortical processing of noxious somatosensory stimuli in the persistent vegetative state. NeuroImage 17(2): 732-741.

Laureys, S., Owen, A. M., and Schiff, N. D. 2004. Brain function in coma, vegetative state, and related disorders. Lancet Neurology 3(9): 537-546.

Laureys, S., Perrin, F., Faymonville, M. E., Schnakers, C., Boly, M., Bartsch, V., Majerus, S., Moonen, G., and Maquet, P. 2004. Cerebral processing in the minimally conscious state. Neurology 63(5): 916918.

Levine, C. 1999. The loneliness of the long-term care giver. New England Journal of Medicine 340(20): 1587-1590.

Michels, R. 1999. Are research ethics bad for our mental health? New England Journal of Medicine 340(18): 1427-1430.

Miller, F. G., and Fins, J. J. 1999. Protecting vulnerable research subjects without unduly constraining neuropsychiatric research. Archives of General Psychiatry 56(8): 701-702.

Miller, F. G., and Fins, J. J. 2005. Protecting human subjects in brain research: A pragmatic perspective. In Neuroethics: Defining the issues in theory, practice and policy, ed. J. Illes. New York, NY: Oxford University Press.

Multi-Society Task Force on PVS. 1994. Medical aspects of the persistent vegetative state (1 and 2). New England Journal of Medicine 330(21): 1499-1508.

Naccache, L. 2006. Psychology. Is she conscious? Science 313(5792): 1395-1396.

National Bioethics Advisory Commission. 1998. Commissioner Statement by Bernard M. Lo with concurrence by Commissioner
Laurie M. Flynn. Research involving persons with mental disorders that may affect decisionmaking capacity. In Report and recommendations of the National Bioethics Advisory Commission, Vol. 1. Arlington, VA.

National Commission for the Protection of Human Subjects. 1978. The Belmont report: Ethical principles and guidelines for the protection of human subjects of research. DHEW Publication No. (OS) 78-0012. Washington, DC: U.S. Government Printing Office.

Owen, A. M., and Coleman, M. R. 2008. Functional neuroimaging of the vegetative state. Nature Reviews Neuroscience 9(3): 235-243.

Owen, A. M., Coleman, M. R., Boly, M., Davis, M. H., Laureys, S., and Pickard, J. D. 2006. Detecting awareness in the vegetative state. Science 313(5792): 1402.

Owen, A. M., Coleman, M. R., Boly, M., Davis, M. H., Laureys, S., and Pickard, J. D. 2007. Using functional magnetic resonance imaging to detect covert awareness in the vegetative state. Archives of Neurology 64: 1098-1102.

Panksepp, J., Fuchs, T., Abella Garcia, V., and Lesiak, A. 2007. Does any aspect of mind survive brain damage that typically leads to a persistent vegetative state? Ethical considerations. Philosophy, Ethics, and Humanities in Medicine 2(1): 32.

Posner, M. I., Sheese, B. E., Odludas, Y., and Tang, Y. 2006. Analyzing and shaping human attentional networks. Neural Networks 19(9): 1422-1429.

Racine, E., Bar-Ilan, O., and Illes, J. 2006. Brain imaging: A decade of coverage in the print media. Science Communication 28(1): 122143.

Raichle, M. E. 1998. The neural correlates of consciousness: An analysis of cognitive skill learning. Philosophical Transactions of the Royal Society of London. Series B, Biological Sciences 353(1377): 18891901.

Reiser, S. J. 1997. The science of diagnosis: Diagnostic technology. In Companion encyclopedia of the history of medicine, eds. W. F. Bynum and R. Porter. New York, NY: Routledge.

Royal College of Physicians. 2003. The vegetative state: Guidance on diagnosis and management. London, England: Royal College of Physicians.

Schiff, N., Ribary, U., Plum, F., and Llinas, R. 1999. Words without mind. Journal of Cognitive Neuroscience 11(6): 650-656.

Schiff, N. D., Giacino, J. T., Kalmar, K., Victor, J. D., Baker, K., Gerber, M., Fritz, B., Eisenberg, B., O'Connor, J., Kobylarz, E. J., Farris, S., Machado, A., McCagg, C., Plum, F., Fins, J. J., and Rezai, A. R. 2007. Behavioural improvements with thalamic stimulation after severe traumatic brain injury. Nature 448(7153): 600-603.

Schiff, N. D., Ribary, U., Moreno, D. R., Beattie, B., Kronberg, E., Blasberg, R., Giacino, J., McCagg, C., Fins, J. J., Llinas, R., and Plum, F. 2002. Residual cerebral activity and behavioural fragments can remain in the persistently vegetative brain. Brain 125(Pt 6): 12101234.

Schiff, N. D., Rodriguez-Moreno, D., Kamal, A., Kim, K. H., Giacino, J. T., Plum, F., and Hirsch, J. 2005. fMRI reveals large-scale network activation in minimally conscious patients. Neurology 64(3): 514523. 
Schnakers, C., Hustinx, R., Vandewalle, G., Majerus, S., Moonen, G., Boly, M., Vanhaudenhuyse, A., and Laureys, S. 2008. Measuring the effect of amantadine in chronic anoxic minimally conscious state. Journal of Neurology, Neurosurgery, and Psychiatry 79(2): 225-227.

Schnakers, C., and Zasler, N. D. 2007. Pain assessment and management in disorders of consciousness. Current Opinion in Neurology 20(6): 620-626.

Singh, J., Hallmayer, J., and J. Illes. 2007. Interacting and paradoxical forces in neuroscience and society. Nature Reviews Neuroscience 8: 153-160.

Staffen, W., Kronbichler, M., Aichhorn, M., Mair, A., and Ladurner, G. 2006. Selective brain activity in response to one's own name in the persistent vegetative state. Journal of Neurology, Neurosurgery, and Psychiatry 77(12): 1383-1384.

Teasdale, G., and Jennett, B. 1974. Assessment of coma and impaired consciousness. A practical scale. The Lancet 2(7872): 81-84.
Vogt, B. A. 2005. Pain and emotion interactions in subregions of the cingulate gyrus. Nature Reviews Neuroscience 6(7): 533544

Voss, H. U., Ulu, A. M., Dyke, J. P., Watts, R., Kobylarz, E. J., McCandliss, B. D., Heier, L. A., Beattie, B. J., Hamacher, K. A., Vallabhajosula, S., Goldsmith, S. J., Ballon, D., Giacino, J. T., and Schiff, N. D. 2006. Possible axonal regrowth in late recovery from the minimally conscious state. Journal of Clinical Investigation 116(7): 18231825.

World Health Organization. 1990. Cancer pain relief and palliative care. Report of a WHO Expert Committee. World Health Organization Technical Report Series 804: 1-75.

Wu, X. H., Zhu, J. H., Gao, L., Zhong, P., Tang, W. J., and Zhou, L. F. 2007. Functional magnetic imaging of brain cortical activities in minimally conscious patients stimulated by visual presentation. Zhonghua Yi Xue Za Zhi 87(27): 1894-1899. 
Copyright of American Journal of Bioethics is the property of Routledge and its content may not be copied or emailed to multiple sites or posted to a listserv without the copyright holder's express written permission. However, users may print, download, or email articles for individual use. 